\title{
Microstructural Differences as a Function of Specimen Position on Base Plate in Additive Manufactured Nickel Based Super Alloy
}

\author{
Yaakov Idell, Carelyn Campbell, Lyle Levine \\ Materials Science and Engineering Division, National Institute Standards and Technology, \\ Gaithersburg, MD, USA
}

Inconel 625 (IN625), which is a solid solution strengthened alloy, is often used in extreme environments such as gas turbine blades, turbocharger rotors, and core components of nuclear pressurizer water reactors. Due to the high nickel content, there is a strong demand to focus research efforts on cost efficient production techniques that will permit novel product designs, which are not easily fabricated through conventional processes. One potential solution is the use of a selective laser sintering technique of additive manufacturing referred to as direct metal laser sintering (DMLS). In this process, a part is built up layer by layer through the melting and subsequent solidification of metal powder particles using a focused laser beam that selectively scans the surface of the powder bed $[1-3]$. The surface layer undergoes rapid solidification as it is melted and cooled during the scanning of the laser beam; however, the underlying layers also experience a variety of heating and cooling cycles leading to potential issues such as high internal stresses, possible part distortion, porosity leading to decreased elongation, and significant surface roughness [4 - 7]. Previous studies have been undertaken to understand the mechanical properties when processing parameters such as energy density, thickness, number of layers, and hatch distance [8 - 12] are altered; however, only a few studies have been conducted to observe the differences in mechanical properties as a function of build location on the base plate [13 - 14]. We initiated a study to understand the microstructural and resulting mechanical property variations as a function of position on the build plate for a given set of processing conditions. In this work, we have focused on microstructural understanding of the specimens, and will conduct mechanical property testing in the future.

Additively manufactured DMLS IN625 specimens were investigated from two different regions of the base plate, the center region and an outlying region. Through the use of scanning and transmission electron microscopy, electron back scatter diffraction (EBSD), and X-ray diffraction, it is shown that build location on the base plate produces significantly different microstructures. Figure 1 shows the obvious morphological differences of the two different specimens as observed by the inverse pole figure (IPF) representations. The specimen built in the center region of the base plate has characteristics with a smaller lattice parameter of the matrix phase $(\approx 0.3593 \mathrm{~nm}$ vs $\approx 0.3603 \mathrm{~nm})$, grain size $(\approx 44 \mu \mathrm{m}$ vs $\approx 57$ $\mu \mathrm{m})$, and aspect ratio $(\approx 2.9$ vs $\approx 4.4)$ as compared to a specimen built in the outlying region of the base plate, which will lead to different mechanical properties such as increased mechanical, fracture, and fatigue strength due to the reduction in grain size and aspect ratio of the specimen built in the center region. Additionally, analysis of the grain boundary character shows a decrease in subgrain and low angle grain boundaries in the center specimen indicating a reduction in stored strain and thus residual stress. All of these indications lead to the likely conclusion that the center specimen receives a higher heat input allowing for additional microstructural processes to occur. The most likely cause for the reduced heat input of the specimen built in the outlying region is the laser beam not being completely orthogonal to the surface due to aberrations in the F-theta lens. Even though the aberrations are typically considered small $(<7 \%)$, it reduces the heat input enough to create significantly different microstructures, which will lead to varying mechanical properties. 
References:

[1] A. Simchi, F. Petzoldt, and H. Pohl, J. Mater. Process. Technol., 141 (2003), p. 319.

[2] A. Simchi, Mat. Sci. Eng. A, 428 (2006), p. 148.

[3] G.J. Booysen et al, Innovative Dev. Des. Manuf., Proc. Int. Conf. Adv. Res. Rapid Prototyping, $5^{\text {th }}, 1$ (2011), p. 145.

[4] P.L. Blackwell, J. Mater. Process. Technol., 170 (2005), p. 240.

[5] J. Delgado, J. Ciurana, and C.A. Rodriguez, J. Adv. Manuf. Technol., 60 (2012), p. 601.

[6] J.P. Kruth et al, CIRP Ann., 56 (2012), p. 730.

[7] Q. Jia and D. Gu, J. Alloys Compd., 585 (2014), p. 713.

[8] M. Islam et al, Phys. Procedia, 41 (2013), p. 835.

[9] C.D. Naiju et al, Adv. Mater. Res., 488 (2012), p. 1414.

[10] D. Gu and Y. Shen, Appl. Surf. Sci., 255 (2008), p. 1880.

[11] J.P. Kruth et al, Proc. Int. Symp. ElectroMachining, $11^{\text {th }}, 1$ (2010).

[12] M. Shiomi et al, CIRP Ann., 53 (2004), p. 195.

[13] M. Schnitzer et al, IEEE Int. Symp. App. Mach. Intell. Info., 1 (2015), p. 31.

[14] C. Casavola, S.L. Campanelli, and C. Pappalettere, Proc. ASME. Int. Mech. Engr. Congr. Expo., 1 (2008).

[15] The use of the Advanced Photon Source at Argonne National Laboratory was supported by the U.S. Department of Energy, Office of Science, Office of Basic Energy Sciences, under Contract No. DEAC02-06CG11357. Certain commercial equipment, instruments, software, or materials are identified in this paper to foster understanding. Such identification does not imply recommendation or endorsement by the National Institute of Standards and Technology, nor does it imply that the materials or equipment identified are necessarily the best available for the purpose.
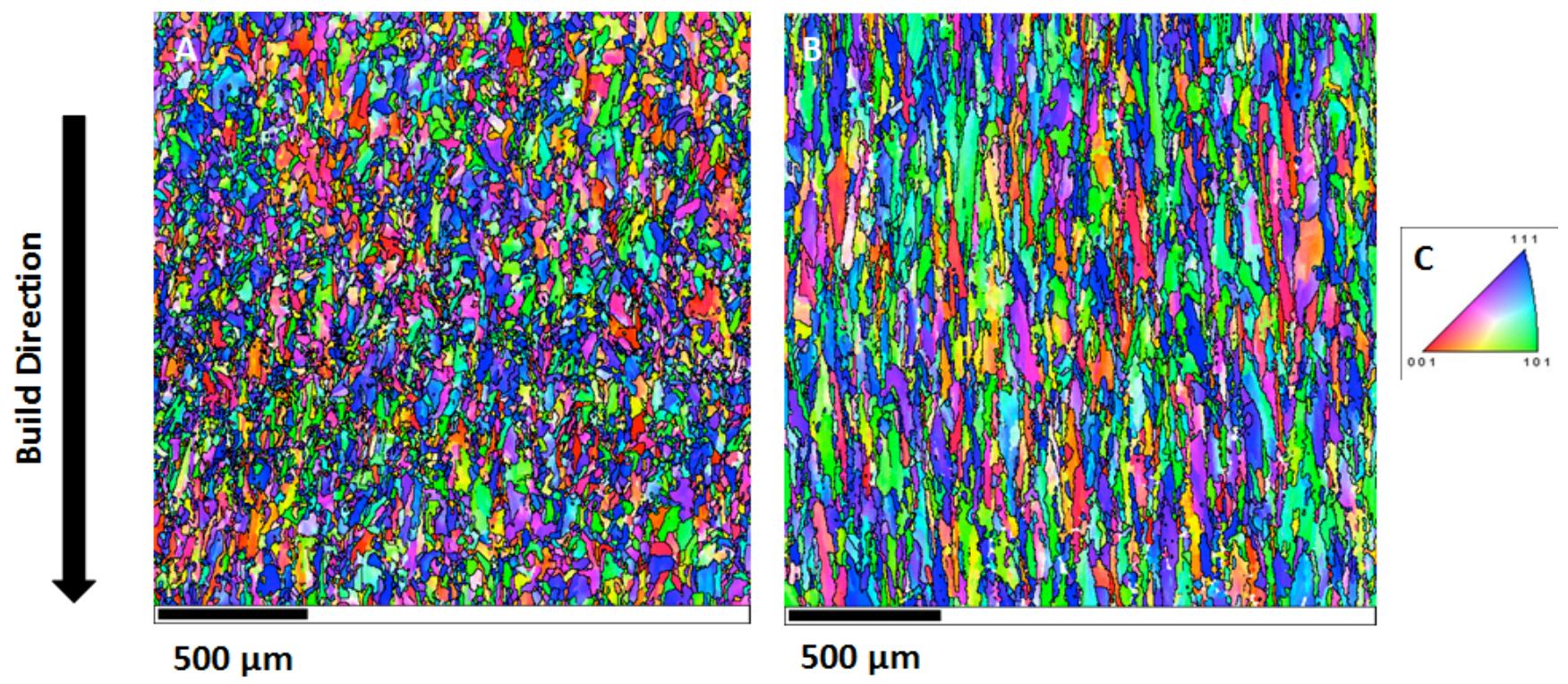

Figure 1. IPF representation of the grain structure of the (a) center specimen and (b) outside specimen along with the accompanying (c) IPF map legend. 